\title{
O primeiro ano de governo de Eduardo Paes na cidade do Rio de Janeiro: uma análise da reforma na educação
}

\author{
The first year of Eduardo Paes' government in the city of \\ Rio de Janeiro: an analysis of the reform in Education ${ }^{1}$
}

\author{
Raquel Pinho ${ }^{2}$ \\ raquel.aps@gmail.com
}

\section{Resumo}

Por meio de uma pesquisa documental, o presente artigo analisa o primeiro mandato do prefeito Eduardo Paes (2009-2012), na cidade do Rio de Janeiro, através dos princípios e valores da Reforma Gerencial de 1995, ocorrida no governo do presidente Fernando Henrique Cardoso. Para tanto, foram analisados os decretos municipais do primeiro ano de mandato (2009) e o Plano Estratégico da Prefeitura do Rio de Janeiro (2009-2012), assim como o próprio documento da Reforma Gerencial de 1995. O trabalho tem por objetivo: i) justificar o primeiro mandato do prefeito Eduardo Paes enquanto um momento de reforma gerencial para a cidade do Rio de Janeiro; e ii) contribuir para a reflexão de como essa reforma impactou a administração escolar e o fazer docente nas escolas públicas municipais.

Palavras-chave: Reforma Gerencial, Gestão educacional, Políticas públicas, Ensino fundamental, Profissão docente.

\section{Abstract}

Through documental research, this article analyzes the first term of mayor Eduardo Paes (2009-2012), in the ci ty of Rio de Janeiro, through the principles and values of Management Reform of 1995, occurred during the President Fernando Henrique Cardoso's administration. In such, we have used the Municipal Decrees of the first year (2009) and the Strategic Plan of the Municipality of Rio de Janeiro (2009-2012), as well as the Management Reform of 1995 itself. The study aims to: i) justify the first term of mayor Eduardo Paes as a moment of managerial reform to the city of Rio de Janeiro; and ii) contribute to the reflection on how this reform impacted the school administration and the teachers' practices in the municipal public schools.

Keywords: Management Reform, Education management, Public policies, Primary school, Teaching profession.

\footnotetext{
${ }^{1}$ Trabalho de conclusão da disciplina Políticas Públicas em Educação do Programa de Pós-Graduação em Educação (PPGE/PUC-Rio), cursada em 2014.2 com a profa. dra. Alicia Bonamino.

2 Licenciada em Ciências Biológicas (IB/UFRJ). Mestre em Educação (PPGE/PUC-Rio). Doutoranda em Educação (PPGE/PUC-Rio), integrante do Grupo de Estudos sobre Cotidiano, Educação e Cultura (Gecec), bolsista Capes.
}

Revista Educação Online, n. 18, jan-mai 2015, p. 96-116 


\section{Introdução}

Durante os anos 1990, houve um movimento de crescente centralidade da gestão e da avaliação na agenda política de modo geral, impactando a política educacional. O Plano Diretor da Reforma e do Aparelho do Estado, também chamado de Reforma Gerencial, implantado em 1995, durante o governo de Fernando Henrique Cardoso ( $\mathrm{FHC})$, indica a existência de três formas de administração pública: patrimonialista, burocrática e gerencial.

A administração patrimonialista ocorre em sociedades pré-democráticas ou pré-capitalistas, nas quais o patrimônio do Estado pertence ao soberano e/ou à sua dinastia. A res publica não é diferenciada da res principis. Esses modelos são encontrados nas monarquias absolutistas europeias até o século XIX.

No fim do século XIX, quando o capitalismo e a democracia se tornam dominantes, a administração patrimonialista se torna insustentável, e a administração burocrática aparece para combater a corrupção e o nepotismo patrimonialistas. Constituem princípios orientadores desse modelo: a profissionalização, a ideia de carreira, a hierarquia funcional, a impessoalidade, o formalismo, o poder racionallegal, o controle a priori e a efetividade. Tal administração sofre grande influência da teoria de dominação legal de Max Weber, pela base no mérito profissional, e da teoria da administração científica de Charles Taylor.

Weber (2009, p. 128-130) nos indica três tipos de dominação legítima: legal, tradicional e carismática. A dominação legal funciona através da disciplina e da consideração de vantagens e desvantagens. É legítima, uma vez que as regras estatuídas estão relacionadas a competências concretas. Tanto quem ordena, quanto quem obedece funciona dentro de leis e regulamentos. Os superiores são escolhidos através de competência, sorte ou eleição. Os funcionários devem possuir formação profissional para exercer o cargo, cujo pagamento está atrelado à hierarquia do cargo e não ao volume de trabalho. O principal tipo de dominação legal é a burocrática e está presente na estrutura do Estado Moderno e em empresas privadas.

Para Lima (2011, p. 131), as perspectivas taylorianas estão presentes em praticamente todos os movimentos das teorias organizacionais e administrativas desenvolvidas no transcurso do século XX. O pensamento tayloriano sobrevive, porque está atrelado à modernização e à racionalidade econômica, ou seja, está atrelado à eficácia, racionalização, alcance de soluções, otimização, progresso, 
melhoramento da relação custo/benefício, desempenho, cooperação, clima favorável e cultura organizacional. Em maior ou menor medida, todos esses princípios estão contidos, de alguma forma, tanto na administração burocrática, quanto na administração gerencial. Essas ideias se perpetuam ainda hoje, mesmo que os meios para chegar a tais fins sejam outros.

No começo do modelo burocrático, o Estado se limitava a manter a ordem, administrar a justiça e garantir os contratos e a propriedade. Com (i) a necessidade de controle dos processos a priori, (ii) o crescente aumento das funções econômicas e sociais do Estado e (iii) o desenvolvimento tecnológico e econômico na segunda metade do século $X X$, a administração burocrática se apresenta como um modelo lento e ineficiente. Surge, então, a administração gerencial, baseada em lógicas empresariais e que carrega os valores: eficiência, qualidade dos serviços públicos, cultura gerencial, controle a posteriori, resultados, produtividade, objetividade, planejamento, autonomia de processos, descentralização de serviços e cidadãocliente, entre outros (BRASIL, 1995, p. 7; LIMA, 2011, p. 139).

Entendendo que no momento de construção da Reforma Gerencial, isto é, no início da década de 1990, nosso país ainda se encontrava em uma administração de tipo burocrática, procura-se criar condições para a reconstrução da administração pública em outras bases, no intuito de criar mais agilidade e eficiência para resolução dos desafios que o país passou a enfrentar diante da globalização econômica. Assim, foi proposta e implantada a administração pública gerencial. Ou seja, o plano de reforma visou à redefinição do papel do Estado, que deixaria de ser o responsável direto pelo desenvolvimento econômico e social, pela via da produção de bens e serviços, para se fortalecer na função de promotor e regulador desse desenvolvimento.

Todavia, a mudança é parcial, pois a substituição do modelo administrativo burocrático pelo gerencial acontece para três dos quatro setores do Estado, sendo eles: núcleo estratégico, atividades exclusivas, serviços não exclusivos e produção para o mercado. No intuito da desburocratização e da descentralização, apenas dois desses setores continuam estatais: núcleo estratégico e atividades exclusivas. Os serviços não exclusivos, que incluem a educação, passam a ser públicos não estatais. E a produção para o mercado é totalmente direcionada para o setor privado (Tabela 1). 


\begin{tabular}{|c|c|c|c|c|c|}
\hline \multirow[b]{2}{*}{ Setores do Estado } & \multicolumn{3}{|c|}{ Tipos de propriedade } & \multicolumn{2}{|c|}{ Tipos de administração } \\
\hline & Estatal & $\begin{array}{c}\text { Pública } \\
\text { não estatal }\end{array}$ & Privada & Burocrática & Gerencial \\
\hline $\begin{array}{c}\text { NUCLEO ESTRATEGICO } \\
\text { Legislativo, Judiciário, Presidência, } \\
\text { Ministérios }\end{array}$ & $\mathrm{x}$ & & & $\mathrm{x}$ & \\
\hline $\begin{array}{c}\text { ATIVIDADES EXCLUSIVAS } \\
\text { Regulamentação, Fiscalização, } \\
\text { Fomento, Segurança, } \\
\text { Seguridade Social }\end{array}$ & $X$ & & & & $\mathrm{x}$ \\
\hline $\begin{array}{c}\text { SERVIÇOS NAO EXCLUSIVOS } \\
\text { Universidades, Hospitais, Centros } \\
\text { de pesquisa, Museus }\end{array}$ & Publicização & $x$ & & & $x$ \\
\hline $\begin{array}{c}\text { PRODUÇÃO PARA O MERCADO } \\
\text { Empresas Estatais }\end{array}$ & Privatização & 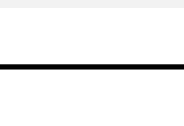 & $X$ & & $X$ \\
\hline
\end{tabular}

Os serviços não exclusivos passam por processos de publicização, isto é, transformações das atuais fundações públicas em organizações sociais. As organizações sociais são entidades de direito privado, sem fins lucrativos, que têm autorização específica do poder legislativo para celebrar contrato de gestão com o poder executivo e assim ter direito à dotação orçamentária. Acredita-se que tornar tais serviços públicos não estatais confere maior autonomia e, portanto, responsabilidade para os dirigentes e gestores. Nessa lógica, também está presente o favorecimento de mecanismos que privilegiem a participação da sociedade, tanto na formulação, quanto na avaliação do desempenho da organização social, instituindo o controle social. Dessa forma, o Plano previa aumentar a eficiência e a qualidade dos serviços, atendendo melhor ao cidadão-cliente a um custo menor (BRASIL, 1995, p. 46-47).

Por ser direcionada a todo o aparelho do Estado, a reforma atinge diretamente a administração das secretarias de educação dos estados e dos municípios e também as administrações das unidades escolares, cujas práticas administrativas aderissem aos valores gerenciais acima citados, a partir do momento da reforma. No campo educacional, para maior autonomia das escolas e diminuição da burocracia no processo de administração escolar, a responsabilidade pela gestão da escola é transferida para a própria unidade. Ao Estado, que deixa de controlar o processo, cabe Revista Educação Online, n. 18, jan-mai 2015, p. 96-116 
controlar os resultados, aplicando avaliações padronizadas aos alunos da rede pública. Contudo, essa autonomia escolar é relativa, pois, na prática, as escolas estão submetidas a orientações gerais, controle de despesas e gestão de pessoal do poder central, além de um sistema de metas de desempenho. A descentralização das decisões periféricas reforça as decisões políticas centrais, consideradas instrumentais relativamente às segundas e delas hierarquicamente dependentes. A autonomia nada mais é do que a diversidade na execução periférica das decisões centrais (LIMA, 2011, p. 170-171).

A avaliação entra nesse contexto como monitoramento, controle e indução de políticas. É através dela, que o nível central realiza um diagnóstico da escola para análise da sua evolução histórica e regula a qualidade de ensino e as diretrizes a serem tomadas para tal. Contudo, é importante destacar o caráter limitado desse diagnóstico, uma vez que a avaliação de rendimento escolar apenas se utiliza da proficiência nas disciplinas de língua portuguesa e matemática, quando muito engloba a de ciências. Não existem instrumentos que possam mensurar nem a proficiência de outras disciplinas, nem os outros saberes escolares que não se restringem aos conteúdos, tais como os sociais e os relacionais. O que observamos a partir daí é uma política de responsabilização, cada vez mais forte, recaindo sobre a gestão escolar (BONAMINO; SOUSA, 2012, p. 375).

No intuito de subsidiar a formulação e a implantação de programas, vemos estabelecidas as avaliações em larga escala e as práticas de accountability. $O$ accountability possui duas dimensões: responsabilização e prestação de contas (BAUER, 2013, p. 330), ambas consideradas a partir de resultados obtidos nas avaliações em larga escola. A responsabilização está relacionada ao gerenciamento da gestão com alocação seletiva de recursos, tendo como contrapartida os resultados obtidos. Já a prestação de contas se dá através do fornecimento de informações à comunidade, às autoridades e à sociedade que propiciem reconhecer se as metas e funções acordadas estão sendo cumpridas. Sobre accountability, Lopes (2014, p. 80) nos aponta sua estreita relação com os processos democráticos, pois pressupõe uma disposição do governo para a prestação de contas à sociedade e para a transparência na manutenção de direitos conquistados. No entanto, o que temos hoje no Brasil é um accountability parcial, um accountability de resultados, uma vez que nossos processos de verificação de resultados se colocam como uma auditoria (buscando falhas no 
processo), e que a ênfase está na responsabilização do corpo escolar docente e administrativo (funcionando em uma lógica de culpabilização).

Nessa perspectiva, trabalho com a hipótese de que, durante o primeiro mandato do prefeito Eduardo Paes (2009-2012), implantou-se uma reforma gerencial no município do Rio de Janeiro, seguindo os princípios e os valores da Reforma Gerencial de 1995, e que essa reforma impactou a administração e o currículo escolares e, consequentemente, o fazer docente. Para analisar essa hipótese, utilizarei alguns decretos municipais assinados pelo prefeito, no seu primeiro ano de mandato (2009), e o Plano Estratégico da Prefeitura do Rio de Janeiro (2009-2012).

\section{Metodologia}

A metodologia utilizada aqui é de natureza documental. "A análise documental busca identificar informações factuais nos documentos a partir de questões e hipóteses de interesse" (CAULLEY apud LÜDKE; ANDRE, 1986, p. 38). Tal técnica utiliza documentos originais, isto é, que ainda não receberam tratamento analítico (HELDER, 2006, p. 1). Destaco que o conceito de documento ultrapassa a ideia de textos escritos ou impressos. Segundo Oliveira (2007, p. 69), documentos usados como fonte de pesquisa podem ser escritos e não escritos, por exemplo: relatórios, reportagens de jornais, revistas, cartas, filmes, gravações, fotografias, entre outras matérias de divulgação. Esses documentos são utilizados como fontes de informações, cujos conteúdos elucidam e servem de prova para algumas questões levantadas pelo pesquisador.

Tendo em vista o recorte temporal estipulado, ou seja, o primeiro ano do primeiro mandato do prefeito Eduardo Paes (2009), realizei o seguinte procedimento para seleção dos documentos. No site de Decretos Municipais da Prefeitura do Rio de Janeiro, fiz uma busca com a palavra 'educação', que resultou em 124 decretos assinados pelo prefeito. Inclui ainda mais dois decretos: 30.555 , de 26 de Março de 2009, e 31.179, de 29 de setembro de 2009, ambos assinados pelo vice-prefeito Carlos Alberto Vieira Muniz, quando em exercício pela ausência temporária do prefeito Eduardo Paes.

Em seguida, os decretos foram lidos e selecionados, de acordo com a presença, em sua redação, de mudanças estruturais e/ou organizacionais propostas pela nova gestão municipal à Secretaria Municipal de Educação (SME) e às unidades 
escolares. Muitos decretos eram referentes ao manejo de verba para adequação orçamentária da SME, os quais não foram selecionados. Portanto, foram separados 12 decretos: 30.339, 30.340, 30.351, 30.352, 30.365, 30.426, 30. 860, 30.861, 30.871, 30.907, 31.157 e 31.614.

Em seguida, repeti o procedimento de busca, dessa vez usando o verbete 'escola'. Foram encontrados 44 decretos, sendo 28 repetidos da primeira busca. Assim, como anteriormente, os 16 novos decretos foram lidos e selecionados de acordo com o conteúdo. Muitos eram referentes às escolas de samba, e foram descartados.

Novamente, encontrei o decreto 31.179, de 29 de setembro de 2009, assinado pelo vice-prefeito Carlos Alberto Vieira Muniz. Destaco que os decretos assinados pelo vice-prefeito não foram selecionados devido ao critério estabelecido: não possuíam, em seu conteúdo, referência a mudanças estruturais e/ou organizacionais da administração.

Foram selecionados mais três decretos na segunda busca: $30.627,30.780$ e 30.932. Sendo assim, no total, separei 15 decretos para compor este estudo. Eles foram retirados na íntegra do site do Diário Oficial do Município do Rio de Janeiro, o que possibilitou uma melhor análise. Também li e analisei o Plano Estratégico da Prefeitura do Rio de Janeiro (2009-2012).

Um dos objetivos deste trabalho é justificar o primeiro mandato do prefeito Eduardo Paes enquanto um momento de reforma gerencial para a cidade do Rio de Janeiro. Por isso, ao analisar os documentos na seção 3, a formatação em negrito será usada para ressaltar as palavras que possuem alguma relação com os valores gerenciais citados na seção 1 . 


\section{A nova gestão do Rio de Janeiro}

Em 2008, Eduardo Paes é eleito para estar à frente da prefeitura do Rio de Janeiro de 2009 a $2012^{3}$. No processo eleitoral de 2008, Eduardo Paes colocou a educação como uma das suas bases de prioridade se eleito. Dentre suas promessas de campanha, estavam ampliar o número de vagas na educação infantil ${ }^{4}$ e terminar com a aprovação automática (progressão continuada) que, desde sua implantação em 2007, pelo então prefeito Cesar Maia, era motivo de muitas discussões e controvérsias. Além dessas, como veremos a seguir, outras medidas significativas foram tomadas, tais como: um sistema de avaliação em larga escala (Ide-Rio), um currículo básico para toda a rede de ensino e o Prêmio Anual de Desempenho para os servidores da educação.

Lançado à época da posse de Eduardo Paes, em 2009, o Plano Estratégico do Rio é um instrumento de atuação em curto prazo pensando em longo prazo. Ele engloba uma diversidade de objetivos, metas e estratégias, que contribuíram para orientar as ações de governo dentro dos quatro anos de mandato.

Podemos ver, ao longo de todo o texto, que mais do que um cliente, o cidadão é visto como um parceiro para alcançar as metas estabelecidas nessa gestão. O primeiro objetivo traçado é "melhorar a qualidade dos serviços públicos prestados no município" (p. 22). Para isso, o plano estabelece princípios de atuação, entre eles: "assegurar uma gestão profissional de toda máquina municipal" (p. 23).

Quatro de suas trinta e sete estratégias traçadas estão na área de educação: Escolas do Amanhã, Espaço de Desenvolvimento Infantil, Reforço Escolar e Saúde nas Escolas (p. 26). Todas as estratégias do governo, tanto para educação quanto para outras áreas figuram dentro de Indicadores de Desempenho. As diretrizes da educação propostas foram (p. 45):

- Construir um processo pedagógico modelo, estabelecendo um padrão de excelência no ensino fundamental e na educação infantil;

- Ampliar o atendimento em creches e pré-escolas, proporcionando um ambiente adequado à criança em seus primeiros anos de vida, com reflexo em seu desenvolvimento físico e mental;

- Capacitar e treinar os professores da rede pública municipal de ensino, utilizando novas tecnologias e construindo, em parceria com universidades e outras entidades, um ambiente moderno e amigável para o ensino a distância.

\footnotetext{
${ }^{3} \mathrm{Em} 07$ de outubro de 2012, o prefeito Eduardo Paes venceu novamente as eleições, conquistando a reeleição com $64 \%$ dos votos válidos, tornando-se o primeiro prefeito da cidade a se reeleger ainda no primeiro turno.

4 Durante o primeiro mandato, a gestão de Eduardo Paes construiu e inaugurou 70 Espaços de Desenvolvimento Infantil (EDI), direcionados para a Educação Infantil.
}

Revista Educação Online, n. 18, jan-mai 2015, p. 96-116 
Enquanto as principais metas incluíam (p. 47):

- Obter uma nota média (entre as escolas públicas municipais) igual ou superior a 5,1, para os anos iniciais, e a 4,3, para os anos finais no ldeb em 2011;

- Criar 30.000 novas vagas em creches públicas ou conveniadas até 2012;

Criar 10.000 novas vagas em pré-escolas públicas até 2012;

- Garantir que pelo menos 95\% das crianças com sete anos de idade ao final do ano de 2012 estejam alfabetizadas;

- Reduzir para menos de 5\% a taxa de analfabetismo funcional entre os alunos do 4ำ ao 6 o ano em 2012;

- Reduzir para menos de $10 \%$ o número de alunos com defasagem idade/série no 6ำ ano em 2012.

Podemos notar um grande foco na gestão, no monitoramento de resultados, na construção de padrões de excelência, no cumprimento de metas e na análise de desempenho. Dessa forma, já no Plano Estratégico existe uma forte presença dos valores gerenciais. Todavia, também carrega alguns valores taylorianos corroborando a colocação de Lima (2011, p. 131), de que esses valores ainda perpassam o pensamento organizacional e administrativo. Nesse sentido, vemos que o documento carrega preocupações com o ambiente favorável, com o clima organizacional, com a capacitação dos profissionais, com o alcance de soluções e com a otimização e o progresso do sistema.

A seguir, analiso os decretos, cujos conteúdos corroboram os princípios gerenciais e taylorianos do Plano Estratégico. O Decreto 30.339, de 01 de janeiro de 2009, dispõe sobre a organização básica do poder executivo municipal. Ele estabelece que a Secretaria Municipal de Educação (SME) estará subdivida em Conselho Municipal de Alimentação Escolar (CAE), Conselho Municipal de Educação (CME), Conselho Municipal de Acompanhamento e Controle Social do Fundo de Manutenção e Desenvolvimento da Educação Básica e de Valorização dos Profissionais da Educação (CMVP) e Empresa Municipal de Multimeios Ltda. (Multirio). Segundo o site da SME, na data do dia 28/07/2009, a missão dessa secretaria contempla:

elaborar a política educacional do município do Rio de Janeiro, coordenar a sua implantação e avaliar os resultados, com o objetivo de assegurar a excelência na Educação Pública no Ensino Fundamental e na Educação Infantil, contribuindo para formar indivíduos autônomos e habilitados a se desenvolver profissionalmente e como cidadãos. Cabe à Secretaria de Educação cuidar da Educação Infantil (6 meses a 5 anos); do Ensino Fundamental ( $1^{\circ}$ ao $9^{\circ}$ ano) e da Educação de Jovens e Adultos do município do Rio de Janeiro. 
O Decreto 30.339 também estabelece as diretrizes básicas da Casa Civil (antigo Gabinete do Prefeito), nas quais podemos observar os valores gerenciais:

modernizar a gestão, avaliar e monitorar a ação governamental e seus respectivos resultados, em especial, das metas e programas prioritários, promovendo ainda a interlocução do Poder Executivo Municipal coma sociedade civil organizada e as outras esferas de governo no trato de assuntos políticos. (grifos meus)

Ainda enfocando a administração municipal, o Decreto 31.614, de 18 de dezembro de 2009, consolida as diretrizes e a regulamentação aplicáveis aos servidores, no que se refere à participação em atividades de treinamento, atualização, reciclagem, qualificação e afins. Segundo art. $2^{\circ}$, tal política de capacitação prevê: (i) promover a melhoria da eficiência, da eficácia e da qualidade dos serviços públicos prestados ao cidadão e a valorização da função pública, por meio de capacitação permanente; (ii) criar e desenvolver hábitos, valores e comportamentos adequados ao digno exercício da função pública; (iii) promover o desenvolvimento permanente das competências e habilidades exigíveis para o atendimento das necessidades da administração pública; e (iv) estabelecer critérios e planejar a efetiva participação dos servidores em ações de capacitação e aperfeiçoamento, racionalizando seus gastos. Vemos que existe uma forte preocupação com a formação do funcionário, para que ele possua as competências necessárias de sua função. Além das dos princípios gerenciais, temos aqui alguns burocráticos. Isso porque, se analisados de acordo com a Reforma Gerencial (1995, p. 48), a administração municipal é uma atividade exclusiva de governo, o que faz coexistir princípios burocráticos e gerenciais, mesmo que a desburocratização venha sendo trabalhada desde o começo da gestão, como aponta o Decreto 30.352, de 1 de janeiro de 2009, que cria o Comitê da Desburocratização no âmbito da Secretaria Municipal de Administração (SMA). Tal decreto impacta diretamente a educação, uma vez que busca promover serviços públicos eficientes e transparentes, a simplificação de procedimentos e 0 estabelecimento de metas de qualidade e produtividade para os órgãos e entidades da administração pública municipal direta e indireta. Também indica como objetivos a otimização das rotinas administrativas em geral e a preferência de meios eletrônicos.

A preferência pelos meios eletrônicos chega à escola como uma obrigatoriedade de implantação do diário de classe on-line. O que inicialmente parecia ser uma otimização da rotina do professor terminou por aumentar a burocracia. Isso porque, muitas escolas não possuem o suporte elétrico, eletrônico e informático 
necessário à instalação dos computadores nas salas de aula. Outro problema é a relação entre depredação/furtos nas escolas municipais e a dificuldade de material humano para a inspeção dos corredores, o que desestimula a instalação dos equipamentos. Dessa forma, muitos professores continuam preenchendo o diário de classe de papel e usam o tempo de planejamento fora da sala de aula para o preenchimento do diário de classe on-line, gastando um tempo precioso de estudo e sistematização de aulas. Infelizmente, muitas das boas estratégias traçadas pela prefeitura e pela SME, ao serem colocadas em prática, são travadas pela infraestrutura física deficiente e pela má gestão de recursos. Os desafios ainda são muitos.

Sobre a questão da racionalização de gastos, o Decreto 30.861 , de 1 de julho de 2009, fixa metas de redução de despesas com serviços públicos - de fornecimento de energia, água e telefonia - no âmbito das escolas públicas. $O$ decreto se justifica (i) pela importância da sustentabilidade; (ii) pela obediência ao princípio da economicidade, eficácia e eficiência da administração pública; e (iii) pelo princípio da isonomia, que implica na garantia de prêmios às escolas que minimizarem os dispêndios, mas também àquelas que já iniciaram tais economias no passado. $O$ valor economizado, ou parte dele, será mantido na dotação orçamentária da própria escola, segundo os critérios abaixo (Tabela 2).

Percentual economizado sobre o total de gastos
com concessionários no mesmo mês do ano anterior
Igual ou superior a $50 \%$

Entre 20\% e $49 \%$

Abaixo de $20 \%$

Tabela 2: Economia nos gastos de serviços e manutenção da receita
Percentual de economia mantido na dotação orçamentária da própria escola
$100 \%$ do total economizado

$80 \%$ do total economizado $50 \%$ do total economizado

Trabalhando ainda no sentindo de desburocratizar, através do Decreto 30.627 , de 24 de abril de 2009, a prefeitura dá uma nova redação ao art. 5ํำ do Decreto 18.437 , de 3 de março de 2000. A partir daí, a prefeitura passa a repassar verba em espécie diretamente à escola, cujo valor será depositado em conta vinculada específica para construção e reforma de escola ou equipamentos urbanos comunitários públicos. Essa iniciativa de descentralização é de extrema importância, pois muitas demandas escolares são urgentes, e o tempo gasto em requerimentos é o diferencial para o bom funcionamento da escola. Por exemplo, se o encanamento de água é rompido ou se 
a fossa da escola entope, entrar com requerimentos e esperar a mobilização da gestão central para a resolução do problema é suspender as aulas por alguns dias, até que a situação se regularize, uma vez que, sem água ou sem banheiros, é inviável receber os alunos. Tendo a verba repassada, a escola pode imediatamente buscar o serviço de reparo e garantir os dias letivos dos alunos. Contudo, ainda existe muita burocracia e pouco material humano, o que muitas vezes impede a real otimização desses processos no cotidiano escolar.

Também na perspectiva de descentralização, o Decreto 31.157, de 22 de setembro de 2009, regulamenta a aquisição de bens e serviços de interesse setorial da SME. Tal determinação considera a necessidade de o município buscar formas mais ágeis de execução dos procedimentos licitatórios, com vistas à otimização da gestão de aquisição de bens e serviços. Por isso, as aquisições de bens e serviços poderão ser licitadas no próprio órgão (art.1\%). Entre os bens possíveis de serem adquiridos de tal forma, temos: o material didático, os uniformes escolares, os kits de material escolar, o mobiliário escolar e os materiais e equipamentos para cozinhas das unidades escolares (art. $2^{\circ}$ ). Entre os serviços, figuram: transporte de alunos para participação em eventos, transporte de alunos portadores de necessidades especiais, infraestrutura para realização de atividades referentes ao desenvolvimento do projeto político pedagógico, capacitação de profissionais da educação, entre outros. Por mais que seja um avanço e garanta mais autonomia para a SME em relação à Prefeitura, não inclui a autonomia das unidades escolares. Como indicado anteriormente, entrar com requerimentos e esperar a mobilização da gestão central para a resolução do problema é correr o risco de suspender as aulas ou de só receber o bem/serviço depois do prazo da necessidade, ficando a escola em funcionamento precário enquanto isso.

Junto com a descentralização, observamos a publicização de serviços não exclusivos. O Decreto 30.780 , de 2 de junho de 2009, dispõe sobre a qualificação de entidades como organizações sociais, que podem se candidatar para diversas secretarias, inclusive a SME, e terão de passar por um Comitê de Qualificação. Vale ressaltar que, no capítulo IV, seção II, art. 31을 sobre a permissão de uso de bens públicos, fica vedado o uso das escolas da rede pública municipal a essas organizações. Complementando o Decreto 30.780, o Decreto 30.907, de 23 de julho de 2009, determina as áreas de atuação das organizações sociais: educação, saúde, 
cultura, esporte e lazer, assistência social, meio ambiente e desenvolvimento tecnológico. As organizações sociais são uma iniciativa já prevista na Reforma Gerencial (1995, p. 44-45), ao indicar que

reformar o aparelho do Estado significa garantir a esse aparelho maior governança, ou seja, maior capacidade de governar, maior condição de implementar as leis e políticas públicas. Significa tornar muito mais eficientes as atividades exclusivas de Estado, através da transformação das autarquias em "agências autônomas", e tornar também muito mais eficientes os serviços sociais competitivos ao transformá-los em organizações públicas não estatais de um tipo especial: as "organizações sociais".

O documento de Reforma Gerencial (1995, p. 60) afirma ainda que a estratégia de transição para uma administração pública gerencial prevê a publicização dos serviços não exclusivos do Estado. As organizações sociais permitem a descentralização de atividades no setor de prestação de serviços não exclusivos, partindo do pressuposto de que esses serviços serão mais eficientemente realizados se, mantendo o financiamento do Estado, forem realizados pelo setor público não estatal. Indo ao encontro da publicização, busca-se uma maior participação social, que estaria presente nos conselhos administrativos das organizações socais.

Outro decreto que incentiva a participação social é o Projeto Apoie uma escola ou creche, sancionado pelo Decreto 30.871, de 06 de julho de 2009, que tem por objetivo o apoio, por pessoas físicas ou jurídicas de direito privado, a unidades escolares ou creches integrantes da Rede Pública do Sistema Municipal de Ensino. $O$ projeto não prevê repasse financeiro, mas um apoio com serviços, custeio de serviços e mão de obra, visando à melhoria da unidade adotada.

Evidenciando as propostas mais relativas ao currículo, aponto o Decreto 30.351, de 1 de janeiro de 2009, que institui um grupo de trabalho para a implantação do regime de horário integral na rede, no qual os tempos adicionais são orientados para atividades extracurriculares, esportivas e culturais ${ }^{5}$.

Ainda em termos curriculares, a intenção de acabar com a aprovação automática concretiza-se em 01 de janeiro de 2009, através do Decreto 30.340, cuja disposição é revogar o Decreto 28.878, de 17/12/2007, que instituiu o sistema de progressão continuada. As principais justificativas são a inadequação do sistema, a necessidade de se estabelecer parâmetros de rendimento e o resgate da

\footnotetext{
5 Em 2010, a prefeitura regulamenta os Ginásios Experimentais Cariocas, de ensino integral, para o segundo segmento do ensino fundamental, que passam a funcionar a partir de 2011 (Decreto 32.672, de 18 de agosto de 2010).
}

Revista Educação Online, n. 18, jan-mai 2015, p. 96-116 
qualidade. Nele, está orientado que cabe à SME editar as normas regulamentadoras do novo modelo de organização da educação fundamental. Além dos valores gerenciais, podemos observar aqui o reforço da autoridade das decisões políticas centrais, no estabelecimento da forma como todas as unidades devem funcionar, criando uma uniformização.

Para Lima (2011, p. 139), a administração escolar é, sobretudo, administração e muito menos escolar, pois está centrada em um discurso racionalmente técnico, que visa à eficácia e ao crescimento da qualidade, o que leva a uma pressão por homogeneidade do sistema. Abrindo espaço para concepções alternativas de qualidade, não seria possível avaliar o sistema para estabelecer comparações, nem premiar resultados. A uniformização possibilita não só estabelecer comparações entre as unidades escolares e com seus próprios históricos de desempenho, mas também permite a transferência de alunos dentro da rede, sem que esse se depare com um currículo radicalmente diferente. Também garante que todos os alunos da rede terão acesso aos conteúdos escolares básicos. Nesse sentido, uniformizar não é destruir as diferenças, as competências e os potenciais de trabalho de cada unidade escolar, mas construir um padrão mínimo, um currículo mínimo, que facilite o trabalho docente e não prejudique os alunos.

Sobre a avaliação escolar na rede pública municipal de ensino, temos o Decreto 30.426, de 26 de janeiro de 2009. Segundo ele, a avaliação, como processo, terá caráter formal, consolidada por meio de provas, testes, pesquisas, trabalhos em grupo e individuais, sem prescindir da autoavaliação, realizada sempre de forma dialógica 6 . Ela deverá ser expressa de forma conceitual: muito bom, bom, regular e insuficiente. Entretanto, a atribuição do conceito global não exclui o registro significativo em cada disciplina. As atividades de recuperação serão desenvolvidas com os alunos que obtiverem conceito global regular ou insuficiente. Ficaram retidos no ano letivo aqueles que, após a recuperação, obtiverem grau insuficiente ou que não apresentarem frequência mínima de $75 \%$ da carga horária total.

\footnotetext{
${ }^{6}$ A resolução da SME 1.010 , de 04 de março de 2009, dispõe sobre as orientações relativas à avaliação escolar na rede pública. Nela, fica determinada a tabela de conversão de notas em conceitos da seguinte forma: de 80 a $100-$ MB (Muito Bom), de 70 a $79-B$ (Bom), de 50 a $69-R$ (Regular), e de 0 a 49 - I (Insuficiente). Além disso, institui que o nível central da SME enviará às escolas, bimestralmente, provas para serem aplicadas a todos os alunos, visando ao acompanhamento de seu processo de aprendizagem. Ou seja, estamos olhando para um transbordamento de avaliações: Provas Bimestrais da SME, Prova Rio, Prova Brasil, ANA e ainda as avaliações cotidianas dos professores, entre outras.
}

Revista Educação Online, n. 18, jan-mai 2015, p. 96-116 
No art. 9², fica estabelecido que a SME realizará, anualmente, uma avaliação de rede, para monitorar e replanejar, sempre que necessário, as suas ações. A partir dos 1990, temos no Brasil o Sistema de Avaliação da Educação Básica (Saeb), cujo principal objetivo é avaliar a educação básica brasileira e contribuir para a melhoria de sua qualidade e para a universalização do acesso à escola. Desde 2013, o Saeb é composto por três avaliações externas em larga escala: Avaliação Nacional da Educação Básica (Aneb), Avaliação Nacional do Rendimento Escolar (Anresc ou Prova Brasil) e Avaliação Nacional de Alfabetização (ANA). Atrelando os resultados médios por escola da Prova Brasil às informações sobre fluxo escolar, foi criado em 2007 o Índice de Desenvolvimento da Educação Básica (ldeb), um indicador de qualidade educacional. Baseado no ldeb, o Índice de Desenvolvimento da Educação do Rio de Janeiro (Ide-Rio) foi lançado em maio de $2009^{7}$, cuja base de medição é a Prova Rio atrelada ao fluxo escolar. A Prova Brasil é aplicada bianualmente a alunos de $5^{\circ}$ e $9^{\circ}$ ano. A Prova Rio é anualmente realizada com alunos de $3^{\circ}$ e $7^{\circ}$ anos.

Ainda no Decreto 30.426, no art. 16을 fica estipulado que o Conselho de Classe será constituído por: diretor ou diretor-adjunto, coordenador pedagógico, orientador ou supervisor escolar (quando houver), todos os professores, dois representantes do Conselho Escola-Comunidade (CEC) e dois alunos, sendo um o representante do segmento aluno no CEC e outro, um componente da diretoria do Grêmio Estudantil. Vemos aqui a participação social prevista na Reforma Gerencial (1995). Mais do que participar, a sociedade também coopera, fiscaliza e cobra por serviços com melhor qualidade. É a lógica da parceria e do controle social, presente no Plano Estratégico do Rio (2009).

Relacionada à avaliação, temos a premiação. O Decreto 30.365, de 01 de janeiro de 2009, dispõe sobre a implantação de um modelo de gestão de desempenho, baseado na construção e no monitoramento de indicadores de performance, que demonstrem a efetividade, a eficácia e a eficiência de cada

\footnotetext{
7 Em comunicado na página 47 do Diário Oficial do Município do Rio de Janeiro, de 29 de outubro de 2009, a SME avisa que a partir daquela data, passaria a medir, a cada ano, o desenvolvimento da educação no município, em português e matemática. A Prova Rio vai gerar o Índice de Desenvolvimento da Educação do Rio de Janeiro (Ide-Rio), que, além de medir o desenvolvimento escolar dos alunos, senvirá de base para a premiação anual dos professores e funcionários das escolas, assumida pela rede para melhorar o ensino. A SME especifica que iria aplicar a Prova Rio para os alunos do $3^{\circ}$ e $7^{\circ}$ anos, pois, dali a dois anos, esse grupo de alunos faria a Prova Brasil. Dessa maneira, a SME teria como acompanhar o desenvolvimento dessas crianças nesse período, tendo assim subsídios para melhorar o ensino.
}

Revista Educação Online, n. 18, jan-mai 2015, p. 96-116 
órgão ou entidade da Administração Pública Municipal. Ele considera que uma administração pública responsável e transparente exige que seus gestores sejam avaliados e recompensados a partir de critérios objetivos, e que a implantação de mecanismos de gestão de desempenho promove as boas práticas de eficiência administrativa e de eficácia nos gastos públicos. Por isso, institui que (I) os gestores de cada órgão ou entidade da Administração Pública Municipal sejam avaliados anualmente; (II) se determine com clareza as penalidades e recompensas que os gestores públicos municipais poderão receber devido à evolução dos indicadores; (III) as diretrizes para que as práticas de gestão de desempenho sejam disseminadas por todos os setores e níveis da administração pública municipal, visando à promoção da meritocracia como um de seus valores fundamentais; e (IV) se implante práticas de gestão de desempenho individuais no âmbito da SME, entre outras secretarias. Nesse decreto, fica claro que a lógica de premiação perpassa toda a rede. Vamos olhar especificamente para a premiação na educação.

Com o Decreto 30.860, de 01 de julho de 2009, a prefeitura dispõe sobre os critérios do Prêmio Anual de Desempenho a ser concedido aos servidores da educação. Esse decreto considera a necessidade de se estabelecerem critérios, padrões e normas de avaliação de desempenho das unidades escolares pertencentes à SME, assim como o reconhecimento das equipes escolares bemsucedidas em termos do processo de ensino-aprendizagem. Segundo o art. $2^{\circ}$, o prêmio será concedido aos servidores que atingirem as metas previstas abaixo (Tabela 3), baseadas no Índice de Desenvolvimento da Educação Básica - Ideb e no Índice de Desenvolvimento da Educação no Município do Rio de Janeiro - IDERio. 


\begin{tabular}{|c|c|c|}
\multirow{2}{*}{\begin{tabular}{c}
\multirow{2}{*}{$\begin{array}{c}\text { Ideb/IDERio do } \\
\text { último período }\end{array}$} \\
\cline { 2 - 3 }
\end{tabular}} & $\begin{array}{c}\text { Anos iniciais } \\
\text { (Fundamental I) }\end{array}$ & $\begin{array}{c}\text { Anos finais } \\
\text { (Fundamental II) }\end{array}$ \\
\hline $2,0-3,0$ & $25 \%$ & $17 \%$ \\
\hline $3,1-4,0$ & $15 \%$ & $12 \%$ \\
\hline $4,1-5,0$ & $12 \%$ & $9 \%$ \\
\hline $5,1-6,0$ & $5 \%$ & $3 \%$ \\
\hline Maior que 6,1 & $2 \%$ & $1 \%$
\end{tabular}

Tabela 3: Metas para o Prêmio Anual de servidores da Educação vigente em 2009

Além da meta de desempenho, outro fator para a premiação é a assiduidade do servidor. Os servidores terão direito ao prêmio, caso tenham no máximo cinco ausências no ano letivo, contando as ausências justificadas (art. $4^{\circ}$ ), sendo concedido da seguinte forma (art. $7^{\circ}$ ): 0 a 2 dias de ausências - $100 \%$ do valor do prêmio; 3 ou 4 dias de ausências - $80 \%$ do valor do prêmio; e 5 dias de ausências - $50 \%$ do valor do prêmio. Como aponta Lopes (2014, p. 74), um ponto relevante do sistema de metas é que não há um número restrito de escolas que podem ganhar o bônus. Como a escola é comparada com ela mesma, alcançar a meta já garante a premiação, independente se o resultado da escola é um dos mais altos ou mais baixos da rede.

Ainda no princípio do mérito e da bonificação, temos o Decreto 30.932, de 30 de julho de 2009, que sanciona o Prêmio Mérito Escolar. Àqueles que, ao final do 9 o ano do ensino fundamental, tiverem obtido, durante todo o ano letivo, nota 9 (nove) e 10 (dez) em todas as disciplinas, e conceito MB (Muito Bom), receberão o prêmio, correspondente a um computador portátil individual (laptop). O decreto se justifica em função do estímulo e do exemplo para motivação de alunos para o estudo e da importância de premiar alunos que se destacam.

As escolas e os alunos com melhores desempenhos são premiados. Mas e as escolas e os alunos com piores desempenhos? Aqueles que obtiveram os desempenhos mais baixos são encaminhados para o programa Nenhuma criança a menos, que prevê que as escolas preparem e apresentem à SME um planejamento para a melhoria do processo ensino-aprendizagem. Para a elaboração desse plano, as escolas contam com a ajuda de escolas que conseguiram os melhores resultados na Prova Rio. Ao longo dessa gestão, a SME também coordenou outros programas, tais como: Projeto Realfabetização, Programa Reforço Escolar, Projeto Acelera, Rio Criança Global e Ginásios Cariocas, com vista à melhoria ou ao aumento da aprendizagem. 
As avaliações em larga escala são usadas, além de monitoramento e controle de resultados, para formular e consolidar projetos. Isso acontece devido aos mecanismos de accountability já adotados. A apropriação da teoria do accountability para área de educação se chama school accountability, ou seja, é o processo de controle, avaliação, responsabilização e prestação de contas do serviço público educacional. São cinco suas principais características: (1) o estabelecimento de padrões educacionais mínimos para cada ano escolar; (2) a realização de testes de proficiência se justifica como o componente que gera dados mensuráveis; (3) a divulgação dos resultados dos testes; (4) o objetivo da política de melhoria dos resultados; e (5) a aplicação de bônus ou sanções de acordo com o desempenho (LOPES, 2013, p. 42-43). Todas essas características são observadas nas propostas da gestão 2009-2012 da Prefeitura do Rio de Janeiro.

Bonamino e Sousa (2012, p. 375) indicam que, no Brasil, ao analisar os desenhos das avaliações, podemos identificar três gerações de avaliações da educação em larga escala, com consequências diferenciadas para o currículo escolar.

No Brasil, avaliações de primeira geração são aquelas cuja finalidade é acompanhar a evolução da qualidade da educação. De um modo geral, essas avaliações divulgam seus resultados na Internet, para consulta pública, ou utilizam-se da mídia ou de outras formas de disseminação, sem que os resultados da avaliação sejam devolvidos para as escolas. Avaliações de segunda geração, por sua vez, contemplam, além da divulgação pública, a devolução dos resultados para as escolas, sem estabelecer consequências materiais. Nesse caso, as consequências são simbólicas e decorrem da divulgação e da apropriação das informações sobre os resultados da escola pelos pais e pela sociedade. [...] Avaliações de terceira geração são aquelas que referenciam políticas de responsabilização forte ou high stakes, contemplando sanções ou recompensas em decorrência dos resultados de alunos e escolas. Nesse caso, incluem-se experiências de responsabilização explicitadas em normas e que envolvem mecanismos de remuneração em função de metas estabelecidas.

A política de premiação do município se enquadra como uma política de terceira geração. Isso porque tem por finalidade atribuir responsabilização forte para os agentes escolares, o que envolve recompensas em decorrência dos resultados de alunos e escolas.

A avaliação em larga escala é um avanço do qual não podemos abrir mão, uma vez que nos possibilita mapear a rede de ensino, avaliando e buscando melhorias para o que não esteja suficientemente qualificado, desde a gestão central até o trabalho docente. Contudo, algumas ponderações são importantes, por exemplo, o currículo escolar fica fortemente atrelado ao conteúdo programático das provas, que, 
mesmo sendo mínimo, amarra o planejamento escolar e docente e dificulta o trato de outros saberes. Além disso, a carga de avaliações imposta aos nossos alunos é muitas vezes sobre-humana e também dificulta o trabalho docente, pois se gasta muitos dias letivos com a aplicação e a correção dessas avaliações. Outro exemplo repousa no fato de que essas testagens são parciais, limitadas a conteúdos de língua portuguesa e matemática, o que não retrata a realidade.

Devemos também atentar para o fato de que existe uma relação forte entre o desempenho escolar dos alunos e a condição socioeconômica de suas famílias, que os bons sistemas escolares conseguem reduzir, mas não eliminar (SCHWARTZMAN, 2011, p. 232). Dessa forma, são necessários mais recursos humanos e financeiros nas escolas públicas, o que muitas vezes é obstruído pelas metas de redução de gastos. Outra característica que incide no desempenho positivo médio dos alunos é uma liderança institucional forte, comprometida com bons resultados, que apoie aos professores e estimule práticas inovadoras. Não basta apenas a premiação, é necessário um sistema institucional de valores que reconheça o bom desempenho dos funcionários, mas que trabalhe para corrigir distorções didáticas e pedagógicas.

\section{Considerações finais}

Em sintonia com as conclusões de Lopes (2014, p. 82), indico que houve uma ruptura do governo do prefeito Eduardo Paes em relação aos governos anteriores, devido à nova gestão enfatizar o planejamento e a avaliação, ao afinamento com as políticas federais e a uma descrença nas políticas tradicionais e/ou anteriores.

Em virtude do exposto, podemos afirmar que tal mandato foi um período de implantação e regulamentação das práticas gerenciais no município do Rio de Janeiro, seguindo os princípios e os valores da Reforma Gerencial de 1995. Essa reforma gerencial do Rio, pautada em planejamento, acompanhamento e corresponsabilização, impactou a administração escolar, o currículo e o cotidiano da escola.

Schwartzman (2011, p. 238) nos indica que colocar a educação como área prioritária de investimento do governo e, em sua gerência, uma pessoa de competência técnica, livre de pressões e compromissos corporativos e políticos, é dar um passo na direção da melhoria da qualidade da educação. Se até a gestão de Eduardo Paes a educação carioca sofria com a ausência de uma política educacional 
clara, podemos dizer que, a partir de 2009, ela está bem definida. Contudo, com uma política educacional focada nos resultados, existe tempo e espaço para os professores planejarem os processos? O professor tem autonomia para definir seus conteúdos? Nesse novo cenário, qual é o papel do professor?

\section{Referências bibliográficas}

BAUER, A. Temas em debate. Responsabilização e prestação de contas na avaliação. Apresentação. Cadernos de Pesquisa, v. 43, n. 148, p. 328-335, 2013.

BONAMINO, A.; SOUSA, S. Z. Três gerações de avaliação da educação básica no Brasil: interfaces com o currículo da/na escola. Educação e Pesquisa, v. 38, n. 2, p.373-388, abr./jun. 2012.

BRASIL. CÂMARA DA REFORMA DO ESTADO. Plano Diretor da Reforma do Aparelho do Estado. Brasilia: 1995.

BRASIL. INEP. Microdados para dounload. Disponível em:

<http://portal.inep.gov.br/basica-levantamentos-acessar>. Acesso em: 20/09/2014.

INEP. O que é o Saeb?. Disponível em:

<http://portal.inep.gov.br/web/saeb/aneb-e-anresc>. Acesso em: 20/09/2014.

HELDER, R. R. Como fazer análise documental. Porto: Universidade de Algarve, 2006.

LIMA, L. C. A escola como organização educativa: uma abordagem sociológica. $4^{a} e d$. São Paulo: Cortez, 2011.

LOPES, K. C. A política de responsabilização educacional do município do Rio de Janeiro. Rio de Janeiro, 2013. Dissertação (Mestrado em Educação) - Universidade Federal do Rio de Janeiro. Rio de Janeiro, 2013.

LÜDKE, M. e ANDRÉ, M. Pesquisa em educação: abordagens qualitativas. São Paulo: EPU, 1986.

OLIVEIRA, M. M. Como fazer pesquisa qualitativa. Petrópolis: Vozes, 2007.

RIO DE JANEIRO. Decretos Municipais. Disponível em:

$<$ http://wpro.rio.rj.gov.br/decretosmunicipais/>. Acesso em: 10/11/2014.

. Diário Oficial Eletrônico do Município do Rio de Janeiro. Disponível em: <http://doweb.rio.rj.gov.br/>. Acesso em: 10/11/2014.

Disponível em: <http://200.141.78.79/dlstatic/10112/2116763/DLFE234720.pdf/planejamento_estrategico_site.pdf>. Acesso em: 15/11/2014.

RIO DE JANEIRO. Secretaria Municipal de Educação - SME. Disponível em: $<$ http://www.rio.rj.gov.br/web/sme/s. Acesso em: 15/11/2014.

SCHWARTZMAN, S. Melhorar a educação no Rio de Janeiro: um longo caminho. In: URANI, A. \& GIAMBIAGI, F. Rio - A hora da virada. Rio de Janeiro: Elsevier, 2011. p. 227-241. 
WEBER, M. Sociologia. Os três tipos puros de dominação legítima. $7^{a}$ ed. São Paulo: Ática, 2008. 